\title{
Fabrication of Flexible Thin Veneer for Electromagnetic Interference Shielding and Decoration through Simple Electroless Plating
}

\author{
Yu Wang, Suri Gala, and Jin Tian Huang *
}

A widely applicable electromagnetic interference (EMI) shielding and decorative thin veneer containing copper was prepared with simple electroless technology. Copper was used as the structural and EMI reflection component to reinforce the mechanical strength and EMI shielding effectiveness. Both the texture and structural properties of copper deposited on poplar wood were characterized. The X-ray diffraction patterns indicated that the copper deposited on poplar wood had a crystallite size between $7.9 \mathrm{~nm}$ and $15.9 \mathrm{~nm}$, and the copper crystallites grew rapidly as the number of electroless runs increased, which was consistent with the resistivity and microscopy analyses. The mechanical and EMI shielding effectiveness results showed that after two electroless runs, the wood veneer surface was completely covered, which improved the EMI shielding effectiveness and mechanical properties of wood veneer. The material could be bent $360^{\circ}$ without being damaged and had a good decorative effect.

Keywords: Electroless; Thin veneer; Electromagnetic interference shielding; Decorative

Contact information: College of Material Science and Art Design, Inner Mongolia Agricultural University, Hohhot, Inner Mongolia, China; *Corresponding author: jintian_h@163.com

\section{INTRODUCTION}

Electromagnetic waves are widely used to carry information in aviation, transportation, the internet, and other industries that benefit humanity. However, electromagnetic waves also have certain hazards, such as affecting human health, reducing the efficiency of instruments, and leaking electromagnetic wave information (Zhang et al. 2011; Zhu et al. 2011; Song et al. 2014). In order to reduce the impact of electromagnetic waves on human production and life, scientists have devoted themselves to research on electromagnetic wave shielding materials for decades. Many materials have been used to shield electromagnetic waves, such as graphene, carbon nanotubes (Tang et al. 2020; Cai et al. 2020; Shi et al. 2019), and metals with good conductivity (Tan et al. 2018). Wood is a renewable resource that is widely used for construction and decorative materials, and it is lightweight and easily processable (Amer 2014). Therefore, as early as 20 years ago, electroless plating technology was used to prepare electromagnetic shielding wood (Nagasawa et al. 1999; Wang et al. 2005, 2006; Wang and Liu 2011). In the following ten years, the form of wood electromagnetic shielding materials has also been expanded, such as electromagnetic shielding particle board and plywood (Wang 2011; Hui et al. 2013, 2014; Pan et al. 2016; Tang et al. 2016).

Wood plated with crystalline copper film can exhibit high electro-conductivity and good electromagnetic shielding effectiveness of over $50 \mathrm{~dB}$ in frequencies ranging from 10 $\mathrm{MHz}$ to $1.5 \mathrm{GHz}$ (Sun 2012). However, wood electromagnetic shielding materials have not 
been widely popularized in China. First of all, Chinese citizens have little understanding of the hazards of electromagnetic waves and very low awareness of protection, resulting in less demand for electromagnetic shielding materials. Second, compared with electroless plating technology, electroplating technology is more mature, and the cost is lower. Third, traditional wood electromagnetic shielding materials (single board, particle board, plywood) have poor flexibility and are not suitable for places with curved surfaces, which limits the scope of application. Finally, for conductive metal-type electromagnetic shielding materials, the key to electromagnetic shielding performance is the continuity of the metal layer rather than the thickness of the metal. Therefore, it is replaced by metal aluminum foil because of its low cost and flexibility (Guo et al. 2016; Zhou and Zhao 2004).

In this study, a method for preparing a flexible, lightweight, and high-strength electromagnetic shielding thin wood using a simple chemical plating technique was developed. The relationship between the number of deposition runs and sample properties was examined, and the copper coatings were characterized.

\section{EXPERIMENTAL}

\section{Materials}

Copper sulfate pentahydrate $\left(\mathrm{CuSO}_{4} \cdot 5 \mathrm{H}_{2} \mathrm{O}\right)$, hydrochloric acid (HCL), sodium borohydride $\left(\mathrm{NaBH}_{4}\right)$, sodium hydroxide $(\mathrm{NaOH})$, seignette salt $\left(\mathrm{C}_{4} \mathrm{O}_{6} \mathrm{H}_{4} \mathrm{KNa}\right)$, ethylenediaminetetraacetic acid disodium salt (EDTA-2Na), and formaldehyde (HCHO) were supplied by Baling Petrochemical (Tianjin, China). Poplar veneer (approximately 0.1 $\mathrm{mm}$ in depth) was purchased from Inner Mongolia Tianyuan Wood Structure Technology Co., Ltd. (Hohhot, China). The ingredients of the active solution and the electroless solution are displayed in Table 1.

\section{Preparation of Composite}

A schematic diagram of copper-plated wood veneer is displayed in Fig. 1. First, poplar was spin-cut into thin wood with a thickness of $0.2 \mathrm{~mm}$, followed by cutting into specimens $(30 \mathrm{~mm} * 30 \mathrm{~mm})$. Before the experiment, poplar veneer was boiled in water at $90{ }^{\circ} \mathrm{C}$ for $90 \mathrm{~min}$ to remove extractive from the wood.

Activation

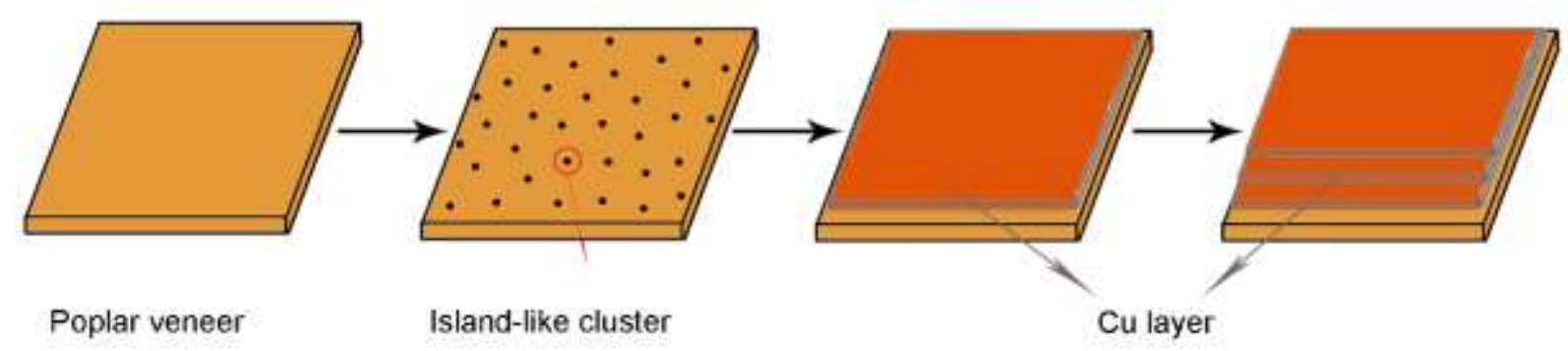

Fig. 1. Schematic diagram of copper plated poplar veneer 


\section{Activation}

The veneer was placed into activation solution $\mathrm{A}$ at $25^{\circ} \mathrm{C}$ for $5 \mathrm{~min}$. The treated sample was then placed into activation solution $\mathrm{B}$ at $25^{\circ} \mathrm{C}$ for $1 \mathrm{~min}$.

\section{Electroless plating copper}

The treated sample was placed into the electroless solution at $65^{\circ} \mathrm{Cand}$ a $\mathrm{pH}$ of 11.4 for $40 \mathrm{~min}$.

Table 1. Ingredients of the Active Solution and Electroless Solution

\begin{tabular}{|c|c|c|}
\hline Solution & Chemicals & Content \\
\hline \multirow{2}{*}{ Active solution A } & $\mathrm{HCL}$ & $12 \mathrm{~mL} / \mathrm{L}$ \\
\cline { 2 - 3 } & $\mathrm{CuSO}_{4} \cdot 5 \mathrm{H}_{2} \mathrm{O}$ & $15 \mathrm{~g} / \mathrm{L}$ \\
\hline \multirow{2}{*}{ Active solution B } & $\mathrm{NaBH}_{4}$ & $15 \mathrm{~g} / \mathrm{L}$ \\
\cline { 2 - 3 } & $\mathrm{NaOH}$ & $12 \mathrm{~g} / \mathrm{L}$ \\
\hline \multirow{3}{*}{ Electroless solution } & $\mathrm{CuSO}_{4} \cdot 5 \mathrm{H}_{2} \mathrm{O}$ & $80 \mathrm{~g} / \mathrm{L}$ \\
\cline { 2 - 3 } & $\mathrm{C}_{4} \mathrm{O}_{6} \mathrm{H}_{4} \mathrm{KNa}$ & $20 \mathrm{~g} / \mathrm{L}$ \\
\cline { 2 - 3 } & $\mathrm{EDTA}-2 \mathrm{Na}$ & $40 \mathrm{~g} / \mathrm{L}$ \\
\cline { 2 - 3 } & $\mathrm{HCHO}$ & $40 \mathrm{~mL} / \mathrm{L}$ \\
\hline
\end{tabular}

\section{Methods}

Scanning electron microscopy

The morphological analyses of the samples were characterized using an S-3400N system (Hitachi Limited, Tokyo, Japan).

\section{$X$-ray diffraction spectra}

The coating structures of the samples were detected via X-ray power diffraction SAXSess $\mathrm{mc}^{2}$ (Anton Paar, Austria, Graz). The patterns were scanned over the angular range of $2 \theta=20^{\circ}$ to $2 \theta=80^{\circ}$.

\section{Crystallite sizes}

The crystallite sizes of copper were determined from the integral breadth of the copper (111) peak using Scherrer's Equation (Eq. 1),

$$
D=\frac{k \lambda}{\beta \cos \theta}
$$

where $k$ is Scherrer's constant $(k=1), \lambda$ is the $\mathrm{X}$-ray wavelength $(\lambda=1.5406 \AA), \beta$ is the integral breadth of a reflection (in radians) located at $2 \theta$, and $\theta$ is the angle $\left(^{\circ}\right)$ of $\operatorname{Bragg}$ diffraction.

\section{EMI shielding effectiveness}

The EMI shielding parameters of copper-plated veneer were analyzed via vertical flange coaxial test device DN15115 model (Quanzhou Meibang Instrument Co., Ltd., Quanzhou, China) in the frequency range of $100 \mathrm{~Hz}$ to $1.5 \mathrm{GHz}$. 


\section{Surface resistivity}

The surface resistivity of the sample was measured by a four-probe meter (RTS-4; Guangzhou Four-Point Probe Technology Co., Ltd., Guangzhou, China).

\section{Mechanical Properties}

Flexural strength was measured by amagnum test machine 5940 (American Instron, Boston, MA, USA).

The interfacial interaction between copper particles and poplar wood was measured by a magnum test machine AG-10TA (American Instron, Boston, MA, USA). In this study, the replication level of all data was 10 . After removing the maximum and minimum values, the average was obtained.

\section{RESULTS AND DISCUSSION}

\section{Morphology Analysis}

The surface morphologies of the coatings with varying numbers of electroless runs are shown in Fig. 2. After one electroless run (Fig. 2a), copper covered the surface of the wood veneer but uncontinuous coating was observed in some positions, and there were some ravines on the surface. This occurred because copper entered into defects and microstructures on the veneer surface, such as pits and ducts, and it could not fill the large voids because an insufficient amount of copper was deposited. After two electroless runs (Fig. 2b), defects on the wood veneer surface were covered, but the size of the copper particles was relatively uneven due to the uneven substrate. After three electroless runs (Fig. 2c and Fig. 2d), the voids and pores were filled with copper, so the wood surface was very smooth. In addition, copper particle size was uniform, and the density was consistent with the low surface resistivity.

Figure 2e depicts the cross-sections of the sample after being copper plated four times to reach a thickness of $140 \mu \mathrm{m}$. The cross-sections of the sample indicated that adherence between copper coatings was excellent. There were no remarkable boundaries between layers when the number of deposition runs was less than four. The pits were filled with copper, which indicated that the binding between wood and copper coating was compact.

\section{XRD Analysis}

Copper-plated wood veneer was prepared via electroless plating, in which copper was produced by a reduction reaction from the solution to the wood veneer surface. Figure 3 shows the XRD pattern of the coated wood veneer. The sharp peaks at $2 \theta=43.44^{\circ}, 2 \theta$ $=50.54^{\circ}$, and $2 \theta=74.44^{\circ}$ were attributed to $\mathrm{Cu}(111), \mathrm{Cu}(200)$, and $\mathrm{Cu}(220)$, respectively. These peaks highlight the face-centered cubic phase of copper. The intensity of the copper (111) peak increased with augmentation of the number of electroless runs. The peak intensity of the wood veneer decreased noticeably as the amount of copper deposited increased. After two electroless runs, the characteristic peaks of wood disappeared entirely, which indicated that the surface was completely covered by copper. As the number of electroless runs increased, the copper coating on the wood veneer surface became more dense and uniform. 

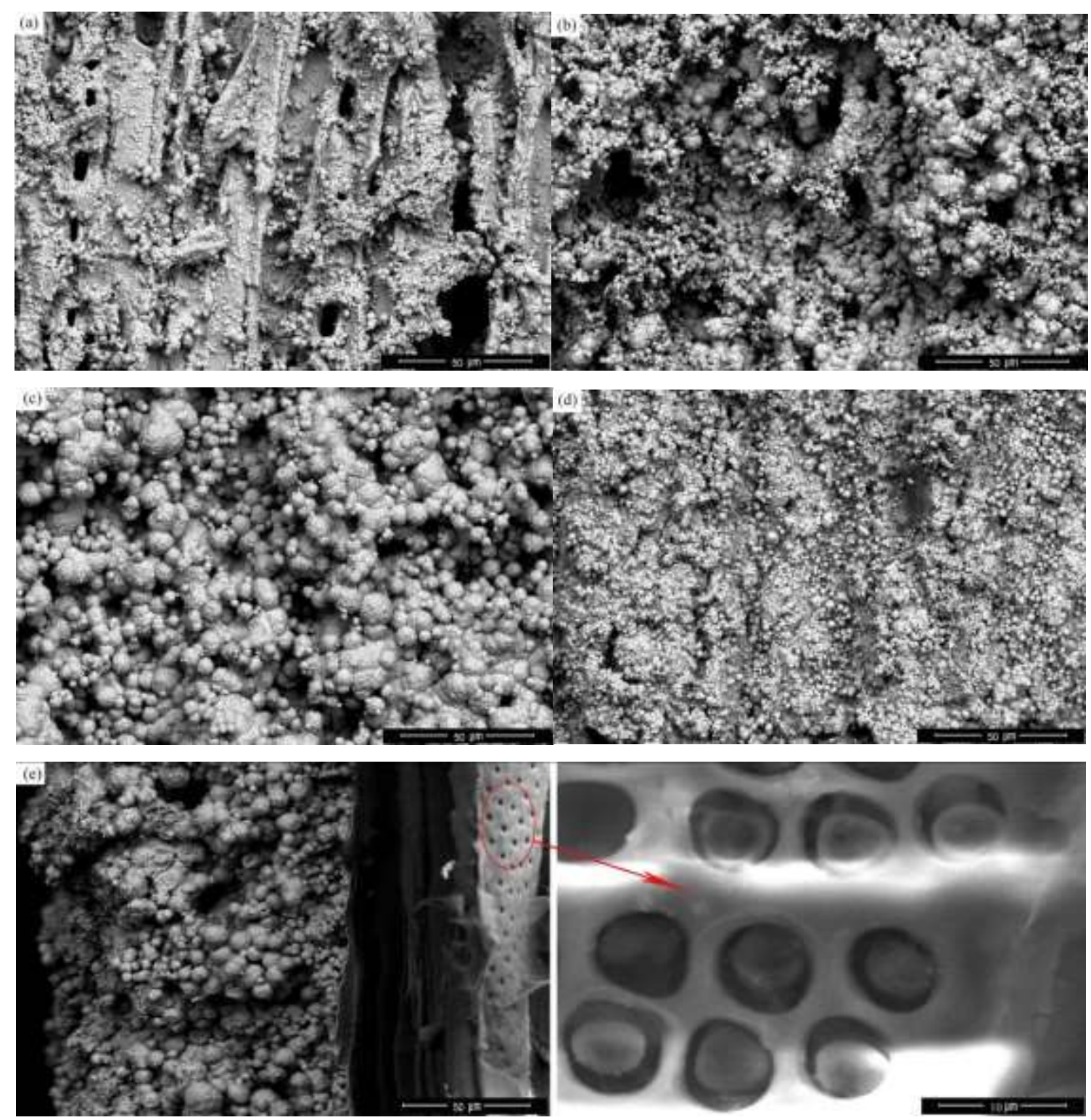

Fig. 2. The surface of copper-plated poplar veneer after one electroless run (a), two electroless runs (b), three electroless runs (c), four electroless runs (d), and the cross-section of copperplated poplar veneer after four electroless runs with and a view of wood microporosity (e)

The results, as shown in Table 2, indicate that the copper crystallites grew rapidly as the number of electroless runs increased. This result occurred because the copper deposited in the former electroless coating had a catalytic effect on the next deposition.

Table 2. Integral Breadth Values and Calculated Values of the Crystallite Size of the Copper (111) Peak as a Function of the Number of Electroless Runs

\begin{tabular}{|c|c|c|}
\hline Electroless Runs & $\begin{array}{c}\text { Integral Breadth } \beta \\
\text { (Radians) }\end{array}$ & $\begin{array}{c}\text { Calculated Crystallite Size } \\
\text { (nm) }\end{array}$ \\
\hline 1 & 1.093 & 7.9 \\
\hline 2 & 0.886 & 9.7 \\
\hline 3 & 0.726 & 11.9 \\
\hline 4 & 0.594 & 15.9 \\
\hline
\end{tabular}




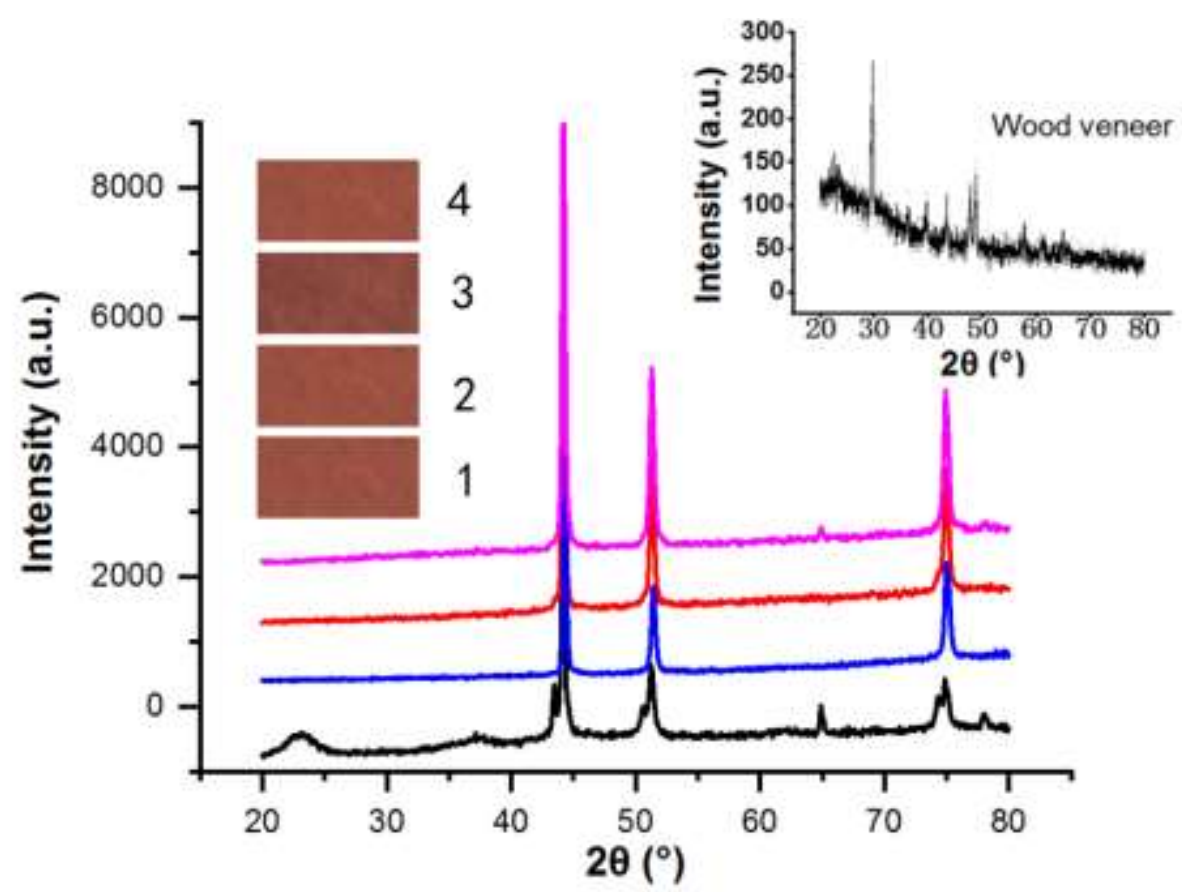

Fig. 3. The XRD spectrum of copper-plated poplar veneer

\section{Surface Resistivity}

The chemical structure of wood does not contain free electrons. Therefore, dry wood is an insulator that has a resistivity ranging from $10^{14} \mathrm{~m} \Omega / \mathrm{cm}$ to $10^{16} \mathrm{~m} \Omega / \mathrm{cm}$. Electroless plating technology can endow wood with excellent electrical conductivity. Surface resistivity of copper-plated wood veneer with different number of electroless runs is shown in Fig. 4.

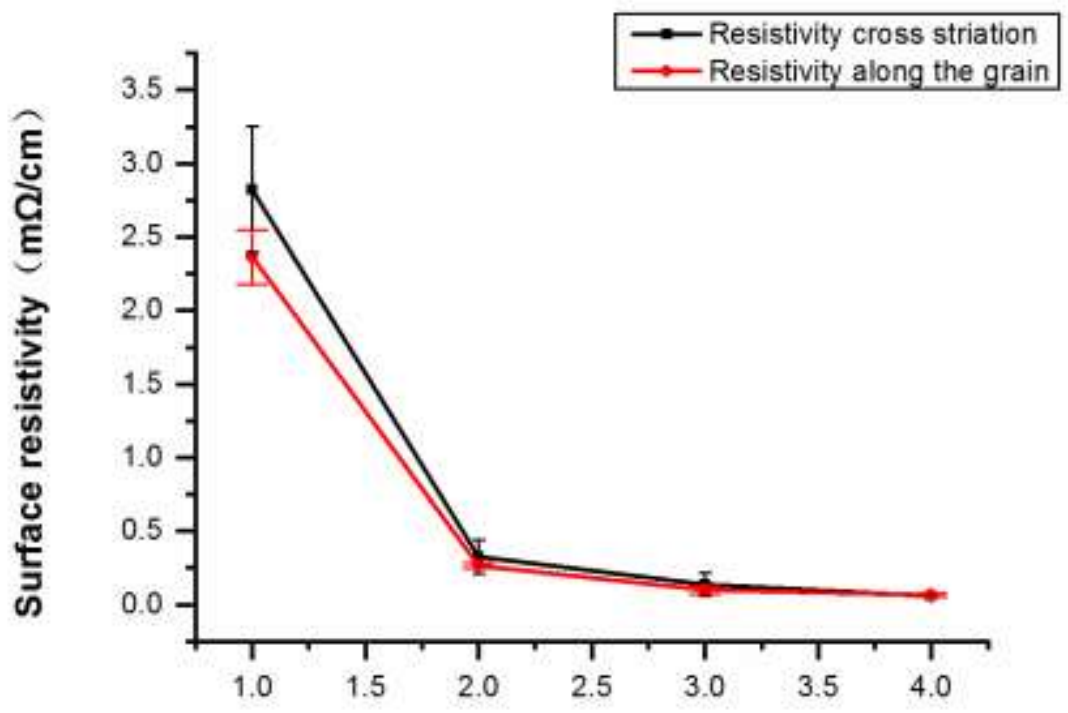

Electroless runs

Fig. 4. The surface resistivity of copper plated poplar veneer after different electroless runs (with the same parameters each time) 
After one electroless run, the surface resistivity was relatively high, and the gap between cross-striation resistivity and along-the-grain resistivity was large. This was because defects perpendicular to the fiber direction, such as voids and catheters in the cell wall structure, were more prominent. Therefore, when metal deposition was low, copper was more likely to form a continuous metal film parallel to the fiber direction. As the number of electroless runs increased, cross-striation resistivity and along-the-grain resistivity both decreased noticeably, and the gap between them became smaller, which indicated that the texture and defects on the surface of the wood veneer had been completely covered by copper. The lowest surface resistivity was close to $0.25 \mathrm{~m} \Omega / \mathrm{cm}$, near to the reported surface resistivity of electroless copper-plated wood (Wang et al. 2005).

\section{EMI Shielding Effectiveness}

Wood has no electromagnetic shielding properties, and electroless copper plating can give the wood metal characteristics that can shield electromagnetic waves. Figure 5(b) displays the EMI shielding effectiveness of wood veneer plated with copper in the range 1 run to 4 runs.

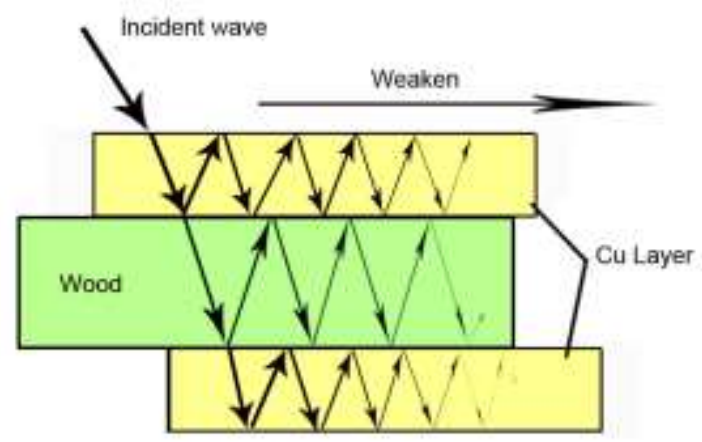

(a)

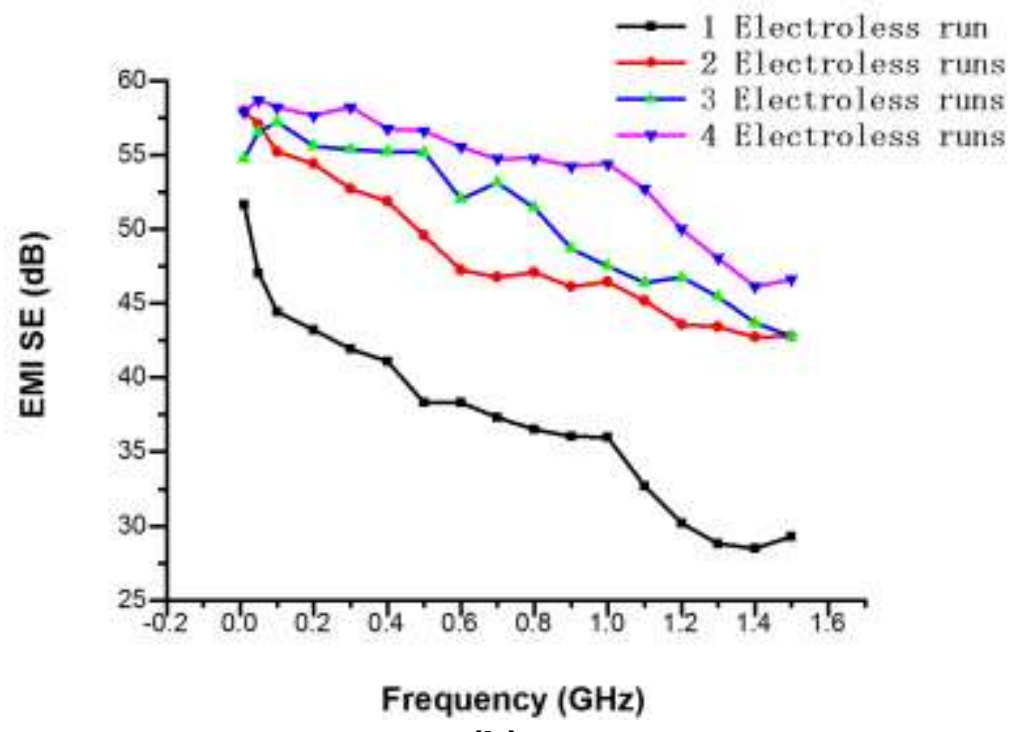

(b)

Fig. 5. Schematic of the mechanism for EMI shielding (a) and EMI shielding effectiveness of copper-plated poplar veneer (b) 
After one electroless run, the wood veneer had good EMI shielding effectiveness under a low frequency. However, as electromagnetic wave frequency increased, the shielding performance fell sharply below $30 \mathrm{~dB}$, which does not meet the civil standard. This occurred because defects on the surface of the wood were fully covered by copper. Further, in some positions, a continuous metal layer was not formed, which allowed penetration under high electromagnetic frequency. After two electroless runs, the EMI shielding effectiveness of wood veneer improved considerably, and the attenuation of shielding effectiveness was limited as electromagnetic wave frequency increased. The electromagnetic shielding performance is not lower than $45 \mathrm{~dB}$ in frequencies ranging from $10 \mathrm{MHz}$ to $1.5 \mathrm{GHz}$., which is close to related literature (Guo 2016). However, as improvement in EMI shielding effectiveness was limited beyond two electroless runs, electroless runs were sufficient to achieve effective EMI shielding.

\section{Mechanical Properties}

Wood veneer cracks easily perpendicular to the fiber direction. As the result of this study indicated that conductivity and EMI shielding performance of wood veneer were stable after two electroless plating runs, the cross-striation mechanical properties of copper plated wood veneer were investigated. Figure 6 shows that the tensile strength of the wood veneer was approximately 1.21 MPa, and after one electroless run, the tensile strength increased to1.84 $\mathrm{MPa}$. After two electroless runs, the tensile strength reached $3.3 \mathrm{MPa}$, which was approximately 2.75 times higher than the tensile strength of wood. However, the tensile strength of samples after three and four electroless plating runs were up to 8.5 and $12 \mathrm{MPa}$, which is far beyond the testing range of the micromechanics experimental machine. Moreover, the samples were very difficult to bend; therefore, there is no value for in-depth research in this study. When tensile strain reached $0.015 \%$, there was a notable fluctuation in tensile strain, which indicated that wood veneer had been broken. As the strain continued to increase, the metal layer supported the tensile load. Figure $6 \mathrm{~b}$ shows the copper-plated thin poplar veneer after two electroless runs, which could be bent $360^{\circ}$ perpendicular to the fiber direction. Therefore, after two electroless runs, copper coating prevented the cracking of thin wood veneer during drying and utilization.

In this study, the tensile strength of the veneer samples after one electroless plating process was indeed lower than that of the thin veneer. The main reason is that lignin, as the "adhesive" of the wood structure, is dissolved by sodium hydroxide (Zhu et al. 2016; Huang et al. 2019). First of all, in order to prepare the electromagnetic shielding thin wood with better bending performance, the thickness of the sample is only $0.2 \mathrm{~mm}$, which is almost translucent, so the mechanical properties of the sample are low. Secondly, the electroless copper plating is carried out in an alkaline environment. The plating solution contains sodium hydroxide, which is used to maintain the $\mathrm{pH}$ of the plating solution at 11.5. However, the electroless copper plating process needs to last about half an hour, causing a considerable amount of lignin to be dissolved. Finally, after one electroless copper plating process, the metal copper content deposited on the sample surface is low, which is not enough to make up for the loss of mechanical properties due to the dissolution of lignin.

The bonding strength of the coating and the substrate is one of the important mechanical properties of the coating. It can be measured by the amount of force required to peel off the coating per unit area. In this study, the straight-pull method was used to test the bonding strength, as shown in Fig. 6(c). 


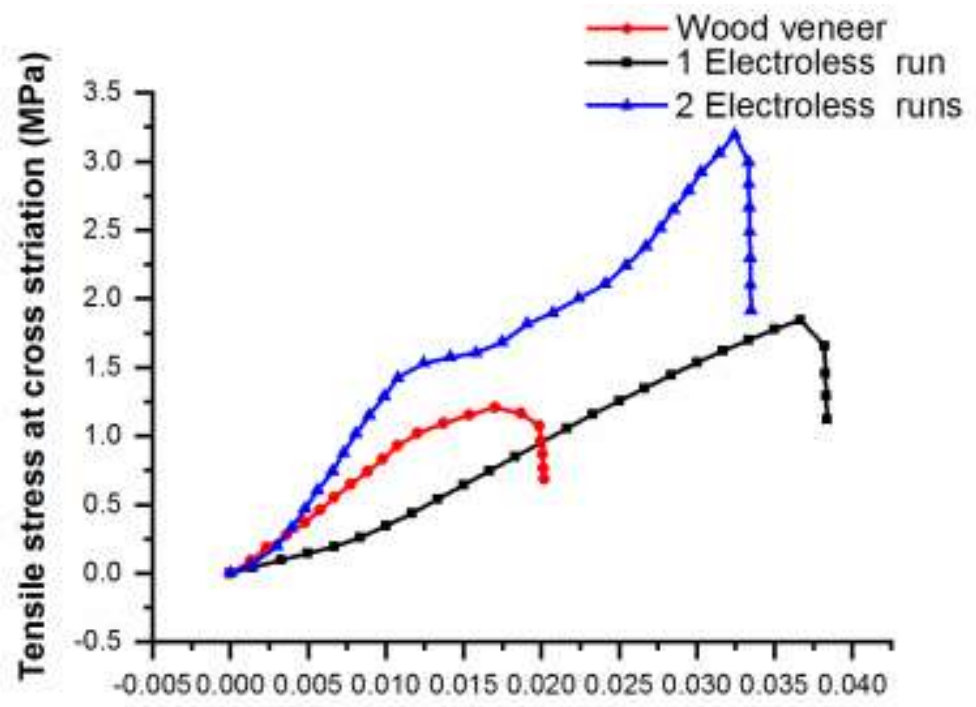

Tensile strain (\%)

(a)

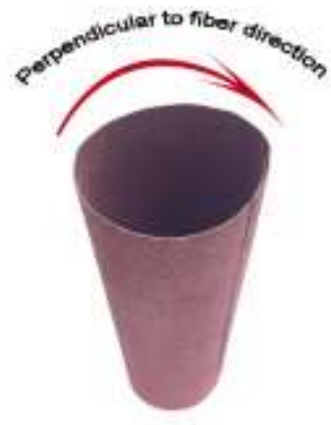

(b)

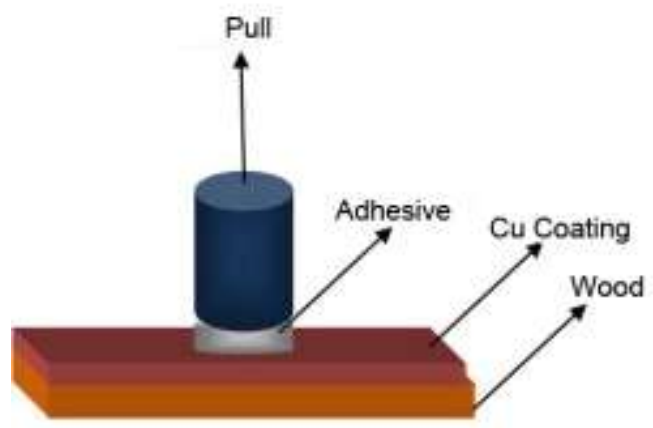

(c)

Fig. 6. The mechanical properties of wood veneer with different electroless plating runs (a); the flexibility of copper-plated thin poplar veneer (b) schematic illustration of vertical pulling test for adhesion (c)

Table 3. Test Results for Adhesion between Coating and Wood Surface

\begin{tabular}{ccc}
\hline Electroless Runs & Bonding strength $(\mathrm{MPa})$ & Failure \\
\hline 1 & 1.4 & Cu coating \\
2 & 2.1 & Wood, Glue line \\
3 & 2.3 & Wood, Glue line \\
4 & 2.4 & Wood, Glue line \\
\hline
\end{tabular}

According to the damage situation in Table 3, except that the damage of the sample after one electroless plating run was in the coating layer, the fracture of other test pieces occurred in the glue layer or the wood itself, and the coating layer did not appear to break. From the analysis of the electroless copper plating process, the $\mathrm{HCOO}^{-}$in the plating solution reduces the complex $\mathrm{Cu}^{2+}$ to the copper element in the pore structure of the wood. 
After the pore structure of the wood was filled, it continued to grow on the surface of the wood, and finally a complete plating layer was formed. The copper deposited in the pore structure of the wood acts as a "wedge nail," which improves the bonding strength between the coating and the wood matrix. In addition, the rugged structure of the wood surface increases the contact area with the plating layer, which further improves the bonding strength.

\section{CONCLUSIONS}

1. A commercially available electromagnetic interference shielding thin veneer made by copper plated on wood was prepared and can be used as a decorative material.

2. Copper crystallites grew rapidly as the number of electroless runs increased. In addition, the copper coating on the veneer surface became more dense and uniform.

3. The vulnerability to cracking of wood was effectively solved by electroless plating. The thin veneer was lightweight and flexible, and it showed promising potential for use in the field of decorative and electromagnetic shielding materials.

\section{ACKNOWLEDGMENTS}

The authors are grateful for the support of the Science and Technology Plan Projects of Inner Mongolia Autonomous Region under Grant No. KCB2018013.

\section{REFERENCES CITED}

Amer, J. (2014). "Influence of multiple electroless nickel coatings on beech wood: Preparation and characterization," Composite Interfaces 21(3), 191-201. DOI: 10.1080/15685543.2014.854615

Cai, J. H., Li, J., Chen, X. D., and Wang, M. (2020). "Multifunctional polydimethylsiloxane foam with multi-walled carbon nanotube and thermoexpandable microsphere for temperature sensing, microwave shielding and piezoresistive sensor," Chemical Engineering Journal 393, article no. 124805. DOI: 10.1016/j.cej.2020.124805.

Guo, T. C., Wang, Y., and Huang, J. T. (2016). "Studies of electroless copper plating on poplar veneer," BioResources 11(3). 6920-6931. DOI: 10.15376/biores.11.3.69206931

Hui, B., Li, J., and Wang, L. (2013). "Preparation of EMI shielding and corrosionresistant composite based on electroless Ni-Cu-P coated wood," BioResources 8(4), 6097-6110. DOI: 10.15376/biores.8.4.6097-6110

Hui, B., Li, J., Zhao, Q., Liang, T., and Wang, L. (2014). "Effect of CuSO4 content in the plating bath on the properties of composites from electroless plating of $\mathrm{Ni}-\mathrm{Cu}-\mathrm{P}$ on birch veneer," BioResources 9(2), 2949-2959. DOI: 10.15376/biores.9.2.2949-2959

Huang, C., Lin, W., Lai, C., Li, X., Jin, Y., and Yong, Q. (2019). "Coupling the postextraction process to remove residual lignin and alter the recalcitrant structures for 
improving the enzymatic digestibility of acid-pretreated bamboo residues," Bioresource Technology 285, article no. 121355.

Nagasawa, C., Kumagai, Y., Urabe, K., and Shinagawa, S. (1999). "Electromagnetic shielding particleboard with nickel-plated wood particles," Journal of Porous Materials 6, 247-254. DOI: 10.1023/A:1009692232398

Pan, Y., Wang, X., and Huang, J. T. (2016). "The preparation, characterization, and influence of multiple electroless nickel-phosphorus (Ni-P) composite coatings on poplar veneer," BioResources 11(1), 724-735. DOI: 10.15376/biores.11.1.724-735

Song, W.-L., Wang, J., Fan, L.-Z., Li, Y., Wang, C.-Y., and Cao, M.-S. (2014). "Interfacial engineering of carbon nanofiber-graphene-carbon nanofiber heterojunctions in flexible lightweight electromagnetic shielding networks," ACS Applied Materials \& Interfaces 6(13), 10516-10523. DOI: 10.1021/am502103u

Shi, Y. D., Li, J., Tan, Y. J., Chen, Y. F., and Wang, M. (2019). "Percolation behavior of electromagnetic interference shielding in polymer/multi-walled carbon nanotube nanocomposites," Composites Science and Technology 170(JAN.20), 70-76. DOI: 10.1016/j.compscitech.2018.11.033.

Sun, L., Li, J., and Wang, L. (2012). "Electromagnetic interference shielding material from electroless copper plating on birch veneer," Wood Science and Technology 46(6), 1061-1071. DOI: 10.1007/s00226-012-0466-y.

Tan, Y.-J., Li, J., Gao, Y., Li, J., Guo, S.-Y., and Wang, M. (2018). “A facile approach to fabricating silver-coated cotton fiber non-woven fabrics for ultrahigh electromagnetic interference shielding," Applied Surface Science 458, 236-244. DOI: 10.1016/j.apsusc.2018.07.107.

Tang, Z., Shi, C., Wu, S., Jiang, Z., and Wang, L. (2016). "Fabrication of hydrophobic surface on wood veneer via electroless nickel plating combined with chemical corrosion," BioResources 11(1), 1007-1014. DOI: 10.15376/biores.11.1.1007-1014

Tang, H. X., Li, J., Tan, Y. Y., Cai, H. J., Liu, J. H., and Wang, M. (2020). “Achieve high performance microwave shielding in poly( $\varepsilon$-caprolactone)/multi-wall carbon nanotube composites via balancing absorption in conductive domains and multiple scattering at interfaces," Applied Surface Science 508, article no. 145178.DOI: 10.1016/j.apsusc.2019.

Wang, L. J., Li, J., and Liu, Y. X. (2005). "Surface characteristics of electroless nickel plated electromagnetic shielding wood veneer," Journal of Forestry Research 16(3), 233-236. DOI: 10.1007/bf02856822

Wang, L. J., Li, J., and Liu, Y. X. (2006). "Preparation of electromagnetic shielding wood-metal composite by electroless nickel plating," Journal of Forestry Research 17(1), 53-56. DOI: 10.1007/s11676-006-0013-5

Wang, L., Li, J., and Liu, H. (2011). “A simple process for electroless plating nickelphosphorus film on wood veneer," Wood Science and Technology 45, 161-167. DOI: 10.1007/s00226-010-0303-0

Wang, L. J., Li, J., and Liu, Y. X. (2005). "Surface characteristics of electroless nickel plated electromagnetic shielding wood veneer," Forestry Research: English Version 16(3), 233-236.

Wang, L., and Liu, H. (2011). "Electroless nickel plating on chitosan-modified wood veneer," BioResources 6(2), 2035-2044. DOI: 10.15376/biores.6.2.2035-2044

Zhang, H. B., Yan, Q., Zheng, W.-G., He, Z., and Yu, Z.-Z. (2011). "Tough graphene-polymer microcellular foams for electromagnetic interference shielding," Applied Materials \& Interface s3(3), 918-924. DOI: 10.1021/am200021v 
Zhou, G., and Zhao, G.-J. (2004). "Development of electroless copper and gold plating on wood," Chinese Forestry Science \& Technology (04), 80-84.

Zhu, M.-W., Song, J.-W., Li, T., Gong, A., Wang, Y.-B., Dai, J.-Q., Yao, Y.-G., Luo, W., Henderson, D., and Hu, L.-B. (2016). "Highly anisotropic, highly transparent wood composites," Advanced Materials 28(26), 5181-5187. DOI: 10.1002/adma.201600427

Zhu, J., Wei, S., Haldolaarachchige, N., Young, D., and Guo, Z. (2011). "Electromagnetic field shielding polyurethane nanocomposites reinforced with coreshell Fe-silica nanoparticles," The Journal of Physical Chemistry 115(31), 1530416310. DOI: $10.1021 /$ jp2052536

Article submitted: February 23, 2020; Peer review completed: April 26, 2020; Revised version received and accepted: May 30, 2020; Published: June 5, 2020.

DOI: 10.15376/biores.15.3.5737-5748 